\title{
HARVARD
}

JOHN M. OLIN CENTER FOR LAW, ECONOMICS, AND BUSINESS

\section{CHOOSING EXPENSIVE TASTES}

Louis Kaplow

Discussion Paper No. 526

$09 / 2005$

Harvard Law School

Cambridge, MA 02138

This paper can be downloaded without charge from:

The Harvard John M. Olin Discussion Paper Series: http://www.law.harvard.edu/programs/olin_center/

The Social Science Research Network Electronic Paper Collection: http://papers.ssrn.com/abstract_id=\#\#\#\#\#\# 
JEL Class D63

\title{
Choosing Expensive Tastes
}

\section{Louis Kaplow $^{1}$}

\author{
Abstract
}

Expensive tastes play an important role in contemporary theories of distributive justice. In particular, some suggest that individuals are not entitled to compensation for low well-being that is attributable to expensive tastes that the individuals have freely chosen. The origins of chosen expensive tastes have not been explored, but they should be. First, the reasons that individuals might choose them could bear on how moral analysis should take them into account. Second, the choice of expensive tastes is prima facie irrational, raising the question whether concern about individuals choosing expensive tastes is warranted in the first instance. This essay considers why, if ever, individuals might choose to develop or adopt what may appear to be expensive tastes, and it suggests that the normative implications of the answers may differ from those ordinarily associated with voluntary rational choice.

Forthcoming, Canadian Journal of Philosophy

\footnotetext{
${ }^{1}$ Harvard Law School and National Bureau of Economic Research. I am grateful to the John M. Olin Center for Law, Economics, and Business at Harvard Law School for financial support.
} 


\title{
Choosing Expensive Tastes
}

\author{
Louis Kaplow \\ C2005 Louis Kaplow. All rights reserved.
}

\section{Introduction}

The possibility that individuals might have expensive tastes is the basis of arguments for and against various theories of how social resources should be allocated. Expensive tastes play a role, for example, in Dworkin's advocacy of equality of resources rather than welfare, in Rawls's account of primary goods, in Scanlon's argument for an objective criterion of well-being, and in Arneson's favoring of equality of opportunity for welfare rather than equality of welfare. ${ }^{2}$

Much of the argument about whether expensive tastes should be treated distinctively concerns whether or not individuals choose to have such tastes. If individuals are simply born with different tastes, or perhaps if they develop them through socialization when young, it is suggested, individuals should not be seen as responsible for their expensive tastes. However, it is argued that individuals should not be compensated for expensive tastes that they have freely chosen - or would hypothetically have chosen - to cultivate. ${ }^{3}$

The present essay focuses exclusively on expensive tastes that individuals decide to adopt

\footnotetext{
${ }^{2}$ Ronald Dworkin, "What is Equality? Part 1: Equality of Welfare," Philosophy and Public Affairs 10 (1981): 185-246, at 228-40; John Rawls, "Social Unity and Primary Goods," in Utilitarianism and Beyond, eds. Amartya Sen and Bernard Williams (Cambridge: Cambridge University Press, 1982), 159-85, at 168-69; Thomas Scanlon, "Preference and Urgency," Journal of Philosophy 72 (1975): 655-69, at 659, 664-65; and Richard J. Arneson, "Equality and Equal Opportunity for Welfare," Philosophical Studies 56 (1989): 77-93. See also Amartya Sen, On Economic Inequality (enlarged edition, Oxford: Oxford University Press, 1997), at 197-98.

${ }^{3}$ See, for example, G.A. Cohen, “On the Currency of Egalitarian Justice," Ethics 99 (1989): 906-44. The alternative (hypothetical) variant is included in order to encompass views under which individuals are responsible for tastes they would have chosen even though they happen to have been born with them or had them inculcated and for tastes that, although not initially chosen, individuals could amend but have voluntarily chosen to retain. To facilitate the exposition, the remainder of this essay will refer to such embraced tastes as included within the category of what will be referred to broadly as voluntarily chosen tastes.
} 
and asks the question: Why would an individual choose to have expensive tastes? ${ }^{4}$ This question should be addressed for two reasons. First, on a priori grounds, it seems that the reason an individual chooses to have expensive tastes might be relevant to whether the individual should be compensated on account of having them. Relatedly, the notion of choice or voluntary adoption of expensive tastes could be understood to have a variety of meanings in the present context, and the answer to the question of what should be deemed a choice and which choices should matter would plausibly be illuminated by considering the bases for individuals' actions that lead them to acquire expensive tastes.

Second, the very notion of choosing to have expensive tastes is prima facie paradoxical. Ceteris paribus, expensive tastes by definition make the individuals who have them worse off, so why would any individual ever voluntarily choose to develop expensive tastes?

In section II, a definition of expensive tastes is offered and this paradox is elaborated, making clear the nature of the conundrum. Section III considers a number of possible answers to the question of why individuals would choose what may appear to be expensive tastes. It turns out that some explanations are unsatisfactory because they do not involve true expensive tastes; that is, on reflection, certain accounts of what seem to be expensive tastes do not constitute such accounts, at least as such tastes are defined here and as seems to be required by the distributive

\footnotetext{
${ }^{4}$ Many who discuss expensive tastes do not explicitly consider why anyone would wish to develop them. Cohen suggests that "there are all kinds of reasons why a person might want to develop an expensive taste" (ibid., 923), but he does not describe any. Perhaps this relative inattention to motivations for developing expensive tastes is because of differences (elaborated in subsection III.A) between the ordinary understanding of the term, where the motivation is straightforward, and its usage as a term of art in the literature under discussion. Dworkin mentions a number of possibilities (which are included among those explored below): "No doubt people often put themselves in the way of new tastes carelessly, or on whim, without considering whether they will really be better off if they acquire these tastes, or even perversely, knowing that they will be worse off. Even when they think they would be better off, they might be mistaken. But I want to suppose that [the individual] is not only acting deliberately rather than inadvertently, but is also acting on the basis of the kind of judgment I said people often make when they form and change their preferences. He is trying to make his life a better life in some way." Dworkin, "What is Equality?," 229-30. Yet his latter statement seems to set aside all of the possibilities he initially mentions, raising the question posed in the text.
} 
theories in question. Another of the candidate explanations does not, upon examination, constitute a credible reason that individuals would adopt expensive tastes. And other explanations, those most capable of explaining how individuals might come to have expensive tastes, may not carry the normative implications that most would associate with voluntary choice. It is not, however, the purpose here to determine the relevance of particular sorts of expensive tastes, however defined, in general or under any particular moral framework. Rather, the intention is simply to illuminate such inquiries by looking behind the idea of chosen expensive tastes.

\section{The Paradox}

\section{A Definition of "expensive tastes"}

It is useful to begin with a definition. An individual will be said to have expensive tastes if he needs more resources to achieve a given level of well-being than if the individual instead had nonexpensive tastes, defined independently (for elaboration, see below). ${ }^{5}$ Three notes about this definition are in order.

First, in this definition, the concept of well-being is employed only for illustrative purposes. One could as easily define expensive tastes by reference to happiness, an individual's sense of the good life (that may include concern for others, moral or otherwise, or a notion of virtue), or some other metric, and the analysis to follow would largely be the same. Accordingly, hereinafter all references to well-being should be taken as a stand-in for whatever it is that individuals may seek in their lives.

Second, it is not claimed that this definition is identical to those in all of the literature.

\footnotetext{
${ }^{5}$ See, for example, Dworkin, "What is Equality?," 228, who refers to those "who need more income simply to achieve the same level of welfare as those with less expensive tastes."
} 
Such identity cannot be assured given that writers typically do not offer a canonical definition and that usage may vary in any event. ${ }^{6}$ As will become clear in section III, however, this definition does allow precise statements about various possible explanations for expensive tastes and thus proves useful for purposes of analysis. Additionally, as it is hoped will become apparent, this definition does seem to capture the essence of what most authors have in mind, even if upon analysis it is not consistent with all of their discussions or examples. ${ }^{7}$

Finally, this definition of expensive tastes directly raises the question of the benchmark for comparison: Just what are the "nonexpensive" or ordinary tastes that serve as the point of contrast for expensive tastes? Do they reflect some average of all individuals' actual tastes? An objective set of tastes? The tastes the individual choosing expensive tastes had previously? Or something else? For present purposes, this question need not be answered except that, when considering individuals who are making choices, it will be assumed that they have at least two alternatives and that one set of tastes is more expensive than the other(s). (Under the theories mentioned in the introduction, however, it may be necessary to say more about the benchmark.)

\section{$B$ Statement of the paradox}

Given this definition of expensive tastes, the paradox is clear. Whatever level of resources an individual might have or expect to have in the future, if he voluntarily chooses to

\footnotetext{
${ }^{6}$ The writers cited in note 1 do appear to have a similar notion in mind, but, for example, Scanlon, "Preference and Urgency," 659, refers to an inability to reach a "normal" level of satisfaction without "very high" expenditures, whereas Dworkin, quoted in the previous note, includes all who require "more income."

${ }^{7} \mathrm{~A}$ taste for a good or service that is expensive but fails to meet the definition in the text appears uninteresting for present purposes. Suppose, for example, that person 1 prefers good $A$, which costs $\$ 5$ per unit, whereas person 2 prefers $B$, which costs $\$ 10$ per unit. If the definition is not satisfied, then person 2 can reach (at least) the same level of well-being as person 1, such as would be possible if person 2's purchase of $B$ produces twice the benefit (in terms of well-being or whatever is the metric) as does person 1's purchase of $A$. Given equal resources, person 1 would purchase twice as many units of $A$ as person 2 purchases of $B$, and each would be equally well off. When individuals prefer different goods, but these preference differences have no effect on their ability to achieve the same level of well-being (or some other desideratum), the issues addressed in the literature on expensive tastes appear to be moot. For further elaboration, see section III.A.
} 
have more expensive tastes, he is choosing to be worse off in terms of well-being (or other pertinent metric). After all, expensive tastes require more resources to achieve a given level of well-being; hence, if one has merely the same resources, one will achieve a lower level of wellbeing.

In many instances, the paradox is even greater. After all, few if any individuals can change their tastes in an instant, by an act of will. Ordinarily, we imagine a process of character planning or inculcation that takes time and involves effort. Consider a simple example in which an individual contemplates developing an expensive taste for fine wine. The individual may need to read books, attend classes and wine tastings, and spend a good deal of money on fine wine before he really comes to appreciate it. Thus, to choose to develop an expensive taste involves: (1) incurring a short-run loss, so that (2) in the long run, one will exist in a state of reduced well-being.

\section{Possible Explanations}

Keeping in mind that this essay considers only expensive tastes that are chosen, rather than those with which one may be born or that may be inculcated at an early age, this section considers a number of possible reasons why someone might think that individuals would make voluntary choices to acquire what may appear to be expensive tastes. As will be seen, some explanations do not involve true expensive tastes at all. Regardless of this consideration, however, it will also be explained that most of the purported explanations do not carry the moral implications for the distribution of resources often associated with expensive tastes.

A Not really an "expensive taste" because satisfaction of it is sufficiently gratifying

The most obvious explanation for an individual's choosing to develop what may seem to 
be an expensive taste is that it is not really an expensive taste as defined here and as seems necessary for the arguments in the pertinent literature. In ordinary parlance, expensive tastes (for fine wine, travel, opera) may be viewed simply as those that are costly to satisfy. However, in many cases such conventionally expensive tastes may be ones that, while costly to satisfy, are sufficiently gratifying to raise the overall well-being of the individuals who have the tastes in question. Presumably, this is what most individuals who attempt to develop so-called expensive tastes have in mind. Often, they are well off financially and may have reached the point where further expenditures on ordinary goods or activities produce very little benefit at the margin. They may have become bored with that which has become customary for them. By cultivating new tastes, they hope to end up in a state in which they are, all things considered, better off. Moreover, they expect to benefit sufficiently to justify the time and expense incurred during any period of investment. When a complete reckoning is made, such individuals are better off for having acquired their so-called expensive tastes; that is, they are able to achieve a higher level of well-being with their available resources.

This everyday understanding of expensive tastes, however, does not correspond to the definition here of such tastes as ones that require more resources to achieve a given level of wellbeing and hence reduce the well-being of individuals who develop them. If there is no such reduction, there of course would be no moral claim to compensation under, say, a theory of equal welfare. (See also the example in note 6.) Indeed, individuals who have successfully developed new tastes, whether conventionally deemed expensive or not, would generally have higher wellbeing than before; that, after all, is likely to be why they would have chosen to develop them. Under a theory of equal welfare, such individuals would receive less, not more, if their new tastes 
- possibly "expensive tastes" - were credited.

\section{$B$ Anticipation of egalitarian compensation}

Perhaps it is imagined that individuals choose to develop expensive tastes (as defined herein) because they anticipate compensation under a regime that implements equal welfare. Although not relevant to the logic of the present argument, it is worth observing as an initial matter that no such explanation seems very likely for expensive tastes presently thought to exist because such a compensatory scheme is not in place. This point is of some conceptual interest because it bears on intuitions regarding examples derived from our current experiences reflecting on our own tastes or those of others. Such reflections are potentially misleading for the present subject because the explanation under consideration pertains not to existing tastes that seem expensive but instead to tastes that might be developed in an imagined compensatory setting.

Now consider whether individuals would rationally choose to develop expensive tastes in anticipation of compensation under a hypothetical egalitarian regime in which compensation was indeed available. Even if there were going to be perfect compensation for expensive tastes, individuals would only be indifferent to developing them. It is not clear, however, why someone would undertake a course of developing new, more expensive tastes such that, after taking into account compensation, he would have precisely the same well-being that he had in the first place. ${ }^{8}$ Also, more realistically, any actual regime probably would not compensate for the investment process, would not compensate immediately upon tastes changing, and would not

\footnotetext{
${ }^{8}$ Interestingly, indifference is achieved in principle only under a regime that implements fully equal welfare. As a contrast, consider a utilitarian regime. If expensive tastes are associated with a lower marginal utility of resources, such a regime would implicitly penalize individuals with expensive tastes by reducing their resource allotment, so developing expensive tastes would be doubly undesirable for them. In such a case, individuals actually would have incentives to develop inexpensive tastes (which, if everyone were to do so, would raise everyone's well-being).
} 
compensate fully (since the regime would not be fully egalitarian, either as a matter of principle or due to considerations of incentives). Thus, individuals who contemplated developing expensive tastes would typically expect to be at least somewhat worse off. ${ }^{9}$

Perhaps the reluctance to credit expensive tastes reflects an implicit concern with the prospect of individuals offering self-interestedly inaccurate depictions of their well-being for purposes of obtaining a greater distributive share. If it is deemed appropriate to compensate for deficits in well-being and if well-being is understood to have subjective elements, then one might imagine relying to an extent on individuals' self-assessments to determine their allotments of resources. Under such a regime, individuals whose circumstances seem objectively adequate might assert that they have expensive tastes (which they in fact have no rational reason to have developed) in order to claim a greater share. ${ }^{10}$ Given this incentive, it probably would be necessary to ignore such undocumented claims, even if it were deemed appropriate in principle to compensate individuals whose well-being was subjectively low. This rationale can justify having the state's distributive apparatus concern itself only with income, primary goods, certain objectively determinable capabilities, or other readily measured indicators of well-being. Note, however, that this justification for eschewing direct assessment of subjective well-being would be instrumental, not an intrinsic rationale as suggested by many who use the phenomenon of chosen expensive tastes to motivate their theories.

\footnotetext{
${ }^{9}$ Individuals in fact will have incentives to develop inexpensive tastes because, by definition, they allow greater satisfaction for a given level of resources. Here, the prospect of a (partial) compensatory response would reduce, but not entirely eliminate, individuals' incentives to develop such tastes.

${ }^{10}$ This concern is raised, for example, by Dworkin, "What is Equality?," 230.
} 


\section{Mistake, weakness of will, and other decisionmaking infirmities}

Individuals might develop expensive tastes inadvertently or due to lack of self-control. They might come upon them wholly by accident, perhaps by attending a party that serves an exotic cuisine that, unbeknownst to them, will prove to be addictive but ultimately unsatisfying. Or individuals might develop expensive tastes through miscalculation, such as by setting upon a course designed to develop new tastes, anticipating them to be more gratifying than they in fact turn out to be or being unaware of the actual expense involved. Or individuals might momentarily succumb to temptation or peer pressure, perhaps knowing at some level that their actions are not in their overall interest.

Such mistakes and the like can occur through lack of capacity, lack of information, or simply bad luck - the latter arising, for example, when one develops a taste that is not at that time expensive but subsequently becomes so due to an unexpected change in market prices. ${ }^{11}$ In this regard, expensive tastes may be seen as akin to a variety of other poor choices individuals might make that have no connection to changes in tastes, like purchasing a home without careful inspection and subsequently discovering a termite infestation, making a foolish job choice, buying a painting while traveling that turns out to clash with one's home decor, eating food that happens to be poisonous due to spoilage, and so forth.

Moral theories differ regarding how society should respond to various types of mistakes, weaknesses, and bad luck. Under some, it might matter whether the bad outcome was due to innate lack of skill or inattention, or whether an undesirable result was due to a decision that was

\footnotetext{
${ }^{11}$ In this regard, note that whether a taste is expensive in any sense depends importantly on the extent to which others share the taste: High demand, through scarcity, may bid up prices or, due to scale economies, may make possible lower-cost production.
} 
objectively poor ex ante or was quite sound but nevertheless resulted in an unlucky outcome.

Furthermore, individuals might obtain various sorts of insurance against both mistakes and bad

luck, such as when they purchase automobile liability insurance or medical insurance. And some moral theories themselves call for society to provide insurance of some sort. ${ }^{12}$

Accordingly, if "chosen" expensive tastes are indeed the product of some types of mistakes and other infirmities, this source may well be relevant to how a moral theory should address the matter. Under many theories, some or all of these sorts of infelicitous decisions would not be treated as morally equivalent to consciously chosen, desired outcomes, which is what many seem to have in mind when they refer to the problem of expensive tastes, seen as the product of individuals' voluntary choices.

\section{$D$ Short-run benefit that exceeds long-run cost}

Yet another possibility is that what may appear to be expensive tastes are in fact advantageous (and thus not "expensive" as defined here) because the process of acquisition involves a benefit rather than a cost, and the benefit is sufficiently large that the individual's well-being is higher overall - that is, taking into account the short-run gain and the long-term loss. This case seems most plausible when the long-term loss is modest since it is presumably incurred for an extended period of time. To illustrate the need to balance gains and losses intertemporally, consider by analogy the choice to go on a vacation that produces a substantial benefit but involves, due to the subsequent need to pay off the debt incurred, modestly reduced

\footnotetext{
${ }^{12}$ An important deterrent to private insurance against mistakes (and a problem with social insurance; compare section III.B) involves the problem that individuals with insurance will take less-than-appropriate precautions. Thus, if insured against accidental development of expensive tastes (by private insurance or egalitarian compensation), individuals - though they would not seek to develop expensive tastes, as explained above - might be less careful about coming to have them accidentally.
} 
consumption for a substantial period thereafter. As long as the benefit from the vacation was sufficiently large - as one presumes is a common phenomenon - such a decision would be viewed as unproblematic even though a snapshot view after-the-fact suggests that the person is worse off as a consequence.

What might be the short-run gain from acquiring expensive tastes? Perhaps the process of developing a new taste is particularly exciting or fulfilling. To some, learning is more exhilarating than actually using what has been learned. For others, the decision to partake in the process may be rewarded by peers, even though it is understood that the ultimate results will not themselves be positive.

In such cases, an assessment of reduced well-being due to expensive tastes would be an incomplete depiction of the individual's overall situation. Viewing the entire time period, the individual is, by hypothesis, better off, not worse off. Just as an egalitarian would not deem worse off someone who has just returned from a delightful vacation - the pleasure, let us suppose, is all in the past - but has not yet paid for it, as in the foregoing example, so too would it be a miscalculation to deem worse off someone who, rationally motivated by sufficient shortrun gains, developed tastes that were somewhat more expensive to satisfy in the long run.

The possibility of short-run benefits does, however, raise certain types of concerns. Sometimes individuals are myopic, overweighting what are truly modest short-run gains and then suffering from nontrivial long-run losses. Common instances include overeating and failing to save adequately for the future. Addiction may be taken as a special case. In these circumstances, the development of expensive tastes is attributed to a sort of decisionmaking infirmity, as discussed in section $\mathrm{C}$, not to ordinary, fully rational, voluntary choice. 


\section{E Different conceptions of well-being}

An individual might rationally choose to develop tastes that lead to an overall increase in well-being as he conceives it but that produce a reduction in well-being as society or some moral theory assesses it. ${ }^{13}$ Such a conflict is possible under some conceptions of well-being, such as objective ones, but not under others, notably a subjective approach that defines well-being in terms of what individuals in fact wish (assuming that the social assessment of individuals' wellbeing is accurate). ${ }^{14}$

It should be emphasized that under the former sorts of theories, it is not just expensive tastes that might be ignored but potentially all tastes, including those for which very high subjective well-being can be achieved with few resources. For example, under an egalitarian theory that calls for an equal allotment of resources independent of tastes, individuals with inexpensive tastes would achieve a higher level of subjective well-being than others. To take another possibility, suppose that under some theory certain tastes do not "count" in the external, objective assessment of individuals' well-being and that an egalitarian outcome in terms of credited well-being (or some other such metric) is desired; in this case, individuals who spend a disproportionate share of their resources satisfying inadmissible tastes would need to receive a correspondingly larger allotment than do others. In any case, problems with individuals' tastes under such theories are due to the tastes' deviation, if any, from the alternative (nonsubjectivist)

\footnotetext{
${ }^{13}$ This possibility is suggested by Dworkin, "What is Equality?," 230-31.

${ }^{14}$ The text oversimplifies. For more complete accounts, see, for example, James Griffin, Well-Being: Its Meaning, Measurement, and Moral Importance (Oxford: Oxford University Press, 1986); Louis Kaplow and Steven Shavell, Fairness versus Welfare (Cambridge, MA: Harvard University Press, 2002), at 418-31; Martha Nussbaum and Amartya Sen, eds., The Quality of Life (Oxford: Oxford University Press, 1993); Thomas M. Scanlon, "The Status of Well-Being," in Tanner Lectures on Human Values, Vol. 19 (Salt Lake City: University of Utah Press, 1998); and L.W. Sumner, Welfare, Happiness, and Ethics (Oxford: Oxford University Press, 1996).
} 
view of well-being, not per se with the high level of expense involved in satisfying any given subjective taste.

\section{Conclusion}

Individuals do not have incentives to choose expensive tastes in the sense that seems to be implied by various arguments about distributive moral principles. Quite to the contrary. If normative theories are to be grounded in concerns about chosen expensive tastes, therefore, further explanation is required. A number of possible accounts of individuals' choice of expensive tastes have been considered here, but some do not really involve expensive tastes in the relevant sense and all of them may have different implications from those that most theories associate with rational, voluntary choice.

One possibility is that existing theories for which the concept of expensive tastes seems central are not mistaken but rather misperceived: If expensive tastes in the relevant sense do not exist - or perhaps arise infrequently, only in narrowly delineated circumstances that may have different normative implications - then aspects of theories built upon them may simply be moot or have little practical importance. Although the pertinent literature does not purport to quantify the significance of the phenomenon of expensive tastes, the impression is that the matter is thought to be of nontrivial significance. Accordingly, the present inquiry suggests that substantial reconsideration may be necessary in light of the underlying sources (if any) of true expensive tastes. 